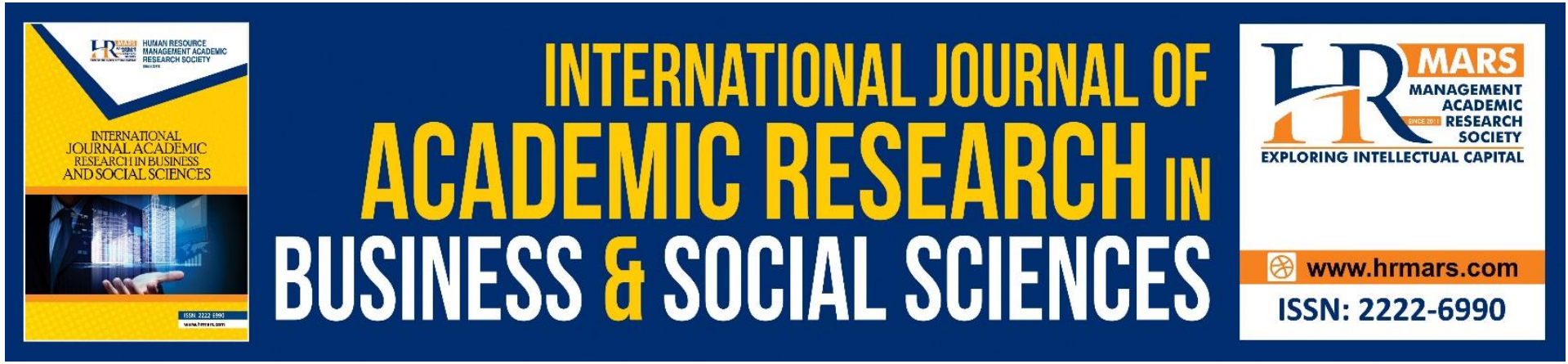

\title{
Higher Education Institutions as Learning Organisations: Learn, Adapt and Evolve
}

Nur Hazelen Mat Rusok, Naresh Kumar Samy and Amiya Bhaumik

To Link this Article: http://dx.doi.org/10.6007/IJARBSS/v11-i7/10566

DOI:10.6007/IJARBSS/v11-i7/10566

Received: 18 May 2021, Revised: 20 June 2021, Accepted: 11 July 2021

Published Online: 25 July 2021

In-Text Citation: (Rusok et al., 2021)

To Cite this Article: Rusok, N. H. M., Samy, N. K., \& Bhaumik, A. (2021). Higher Education Institutions as Learning Organisations: Learn, Adapt and Evolve. International Journal of Academic Research in Business and Social Sciences, 11(7), 1003-1015.

Copyright: (c) 2021 The Author(s)

Published by Human Resource Management Academic Research Society (www.hrmars.com)

This article is published under the Creative Commons Attribution (CC BY 4.0) license. Anyone may reproduce, distribute, translate and create derivative works of this article (for both commercial and non-commercial purposes), subject to full attribution to the original publication and authors. The full terms of this license may be seen

at: http://creativecommons.org/licences/by/4.0/legalcode

Vol. 11, No. 7, 2021, Pg. 1003 - 1015

http://hrmars.com/index.php/pages/detail/IJARBSS

JOURNAL HOMEPAGE

Full Terms \& Conditions of access and use can be found at http://hrmars.com/index.php/pages/detail/publication-ethics 


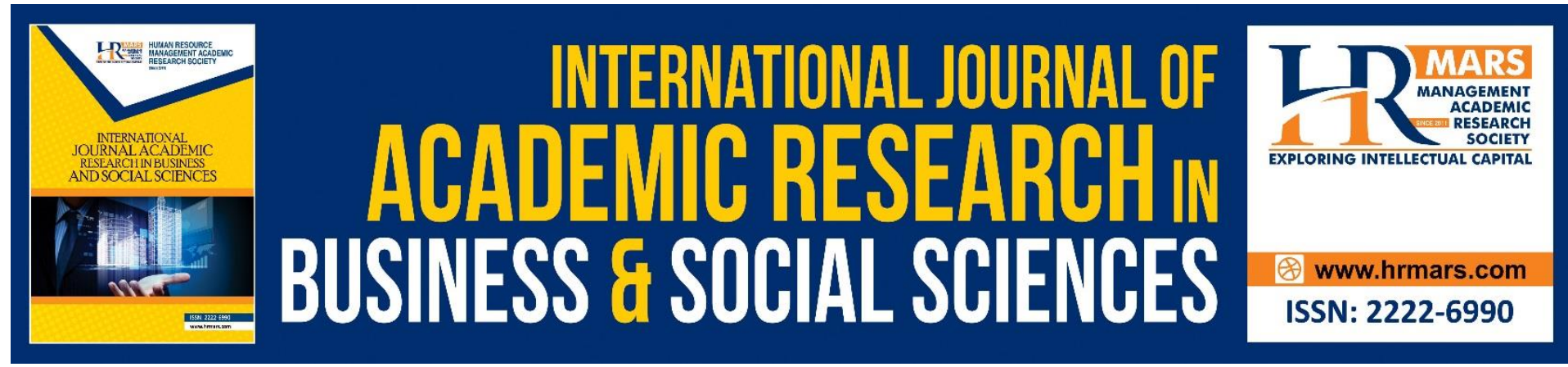

\title{
Higher Education Institutions as Learning Organisations: Learn, Adapt and Evolve
}

\author{
Nur Hazelen Mat Rusok ${ }^{1}$, Naresh Kumar Samy² and Amiya \\ Bhaumik $^{3}$ \\ ${ }^{1}$ Faculty of Business and Management, Universiti Teknologi MARA, ${ }^{2}$ Faculty of \\ Entrepreneurship and Business, Universiti Malaysia Kelantan, ${ }^{3}$ Lincoln University College, \\ Malaysia
}

\begin{abstract}
The industrial revolutions pave the way for higher education institutions (HEIs) to remain competitive while infusing relevant knowledge into society. The recent COVID-19 pandemic spawns many new challenges, but HEls that are already in the paradigm of the learning organisation swiftly reshaped the provision of educational services. The digitalisation of teaching and learning is not new for learning organisations; indeed, learning management systems usage mounted during the global COVID-19 pandemic. Besides, HEls use social media platforms to provide continuous quality education supports to learners. The adoption of digital technologies in HEls will continue rapidly, and indeed we have withness the digital evolutions in the past. Following this, new challenges to the assurance of quality and standards are likely to emerge. HEls as learning organisations realise that they can improve academic quality and standards through continuous learning and change efforts. With this in mind, HEls are encouraged to reinforce the fundamentals of a learning organisation culture within the educational ecosystem. The commitment to quality assurance lead to conscious recognition of strengths and opportunities and monitor treat and weaknesses. Advancing standards and quality of education benefit all, not least to HEls themselves. This paper attempts to reinforce the role of HEls as learning organisations that helps to narrow or even eliminate the knowledge gaps in the global knowledge economy.
\end{abstract}

Keywords: Learning Organisation, Knowledge, Higher Education, Institution, Quality Assurance

\section{Introduction}

COVID-19 has led to profound effects on the global education sector due to the dramatic economic volatility. Majority of HEls that surviving the COVID-19 pandemic most likely encounter declines in income and increases in operating budgets. Two common scenarios visible during the COVId-19 challenges, private HEls will be hard-pressed since their profit or loss depends on local and international students' intake and tuition fee collections. Second, the public HEls will undergo deep budget cuts due to reducing economic activities and national income. In the past, both developing and developed countries witnessed economic instability that necessitates business organisations includes HEls, to perform 
restructuring strategies to strive for survival and, to the worse extent, cease the operations. As the HEls matures with experiences from their learning of past events, we remain optimistic that their leaders have the best alternative strategies to balance human resource welfare with current situations and keep pace with high work commitments. COVID-19 pandemic overturning workplace and paves new norms to cultivating innovative work behaviour.

Meanwhile, HEls are conscious of their requirements always to be ready to fulfil the demands of learners for new-fangled knowledge to move steadily in today's civilised community. Those HEls already embracing the learning organisation setting anticipated to have contingency plans to achieve superior, innovative work behaviour among their employees with better financial and non-financial results. HEls ability to learn and translate that learning into action rapidly is the ultimate mean of competitive advantage. The purpose of this paper is to reinstate strategies that HEls put in place to deal with the present and postCovid-19 pandemic.

\section{Methodology}

The conceptual paper critically reviewed existing knowledge on learning organisation dimensions. It proposed its significance to HEls in sustaining educational qualities and fulfilling contemporary skills demands. There is comprehensive research work in this area, but the ideas are scattered, focusing more on business organisations. This study reinforces the learning organisation principles and importance to HEls competitiveness. Besides, this paper helps guide future research that may use a quantitive or qualitative approach in business and non-business contexts. This paper aims to enrich the body of knowledge in organisational learning and show that the dimensions associated with it remain germane to date.

\section{Readiness of the HEls}

Transformations in planning, developing, organising, distributing, and evaluating advanced knowledge with disruptive technologies are essential business norms in pre-and post-COVID-19 pandemics. Creating applications-based knowledge for diverse learners and accommodating individual expectations is one of the specific focuses of HEls. Following that, HEls need to build understanding through research and development activities and nurture society's talent to respond to the living of boundaryless global fraternity. HEIs can overcome the pressures of the COVID-19 pandemic with professional learning and development activities. The underlying principles of the learning organisation are the remedy that needs to reinforce in the education ecosystem (Miller, 2021).

The growth of intellectual capital is the keystone for national progression, and that HEls redesign educational strategies to address a massive increase in the demand for futuristics educational services. Moreover, being alert to the present industrial pressures towards the workforce resulting from the advancements in the business revolutions. Therefore, urge HEls to involve actively in developmental activities to prepare the future workforce with impactful knowledge, skills, attitudes and aspirations to join industrial processes with complete confidence. The phenomenon of the knowledge economy challenges HEls to advance a diverse workforce. The competencies required to manage a modern working environment are substantially more demanding than in past decades, considering the demands for innovative learning methods resulting from a comprehensive volatile economy. 
Skills to function effectively in modern workstations evolve and necessitate individuals who have the purchasing power to look forward to updating their skill sets continuously. Eventually, it increases the number of adult learners looking for HEls to obtain a credential that will grant entrance to their professional hierarchy (Akella, 2021). Furthermore, selecting a program of studies also relies on survival prospects in a global knowledge economy. Technological advances and innovations will undoubtedly lead to a complex world, which demands a more qualified workforce. High productivity growth rates are possible if society continually participates in learning or skill development activities throughout their lives. As a result, individuals can contribute to their communities' development and live up to their potentials. Thus HEls must provide individual learners with eminence education with industrial relevant skills and knowledge to adapt to the changing labour market needs. Over the past decade, the increase in adult learners forced HEls to address the changing labour market, provide good hands-on skills, and develop economic competitiveness. Therefore, HEls swiftly devote themselves to shaping the curriculum and process for human capital growth to achieve sustainable development.

The workforce's constant advancement helps reach the pleasant quality of work-life, which relies upon education. Indeed higher education is regarded as causative to the attainment of individual sovereignty, the rise of knowledge and social and economic progress. Traditional HEls faces new challenges in providing education to concerned learners, and the challenges are even more prominent in developing countries. In the global educational system, quality of knowledge creation is the main ingredient besides advanced technological tools. The industrial revolutions have placed innovation and information flow a top priority for economic efficiency (Battistella et al., 2021).

Moreover, the rapid breakthroughs in information technologies and continuous diversification of knowledge make it extremely necessary for HEls to widen pedagogical methods and curricula. Meanwhile, HEls should take into account that they should achieve social goals and meet their societal expectations. Specifically, HEls are encouraged to reconfigure their education policy according to the current global economy demands (Ashour et al., 2021). The rationale for education policy reconfiguration is to strengthen the workforce competencies, providing a solid platform for national development in this futuristic competitive international arena. HEls should ensure a balanced achievement of their educational and institutional mission, academic excellence and high-quality educational programs along the lines of society demand. In addition, HEls must build a lifelong learning culture in the society and magnify the educational provisions, which will significantly help overcome the consequences of economic reform.

HEls, with their role as a knowledge factory, must adopt entrepreneurial strategies that gradually change their institutional culture. The inadequate institutional resources, mounting educational costs, and growing demand for accessibility and justness have generated external pressures on HEls to become more accountable to their funding sources. HEls need to reorientate their strategies in equipping state-of-the-art facilities that keep everyone motivated in the teaching-learning endeavour with the available operation and development budgets. However, the provision of top-notch educational tools requires more funds. Public HEls must be self-reliant regarding fund generation while focusing on 
their establishment purposes rather than being too dependent on government alone. The HEls must engage in profit-making ventures to raise funds and add learning technology that matches the present education industry. The financial strength means getting closer to the education and quality revolution of HEls.

A competitive global knowledge economy creates limitless learning opportunities. HEls make their presence physically and virtually to engage the learners with their services worldwide. It is an opportunity that all HEls exploring more aggressively to continue the flow of income. Yorke (1999) said long ago that higher education supports the indigenous labour force's development and helps raise national income. It is noticeable that HEls are integral to providing and expanding essential civic and social ideals besides their primary role to produce skilled and knowledgeable workers capable of adjusting to workplace realities. A wellrounded and disciplined workforce certainly increases competence and will make sure that the economic development is equally resilient and sustainable in the future.

Every nation is competing for a better life. An innovative and creative society with advanced ICT literacy is essential for economic growth and sustainable development in the knowledge economy. As employers increasingly require manifold skills and knowledge from the workforce, quality education systems with a noble assurance of learning framework are vital to ensure an adequate flow of qualified and highly skilled human resources placed in the economy. HEls must extend the quality education opportunities, which provides employability and a comfortable standard of living. Participation of HEls in the knowledge economy is crucial means for sustainable socio-economic growth. Although quality assurance seems to be challenging, the notion of quality assurance remains a vigorous area of debate in the literature of higher education. Quality assurance in HEls is initiatives taken by institutions to accomplish their intended objectives, comprising educational standards and quality. Educational standards are the level of achievement that a learner has to reach to gain an academic award-continuous learning opportunities coupled with effective coaching and support to obtain that award viewed as educational quality.

There is no doubt that HEls continue to play a vital role in assuring higher education standards as stipulated in their respective educational vision and mission. Academic standards are not static but dynamic and change from time to time. Indeed developing countries must ensure that the disparity in principles and criteria applied for quality assurance in HEls at developed countries are narrowed down or probably does not exist. Advances in ICTs ease the participation in international networks, which can help the HEls worldwide update current developments and changes in quality assurance principles and standards (Ashour et al., 2021). In addition, there is a consensus on the need for regional and international cooperation in strengthening the structures of the educational system. Globalisation in education created opportunities for HEls to extend their functional role by offering educational programs through franchise institutions, branch campuses, and online learning modes. Student options for education, in particular, are no longer constrained by national boundaries due to the rapid innovation forms of international education. HEls, strive to provide a high quality of education for their diverse learners and ensure that academic standards constantly meet the expectations. Quality and relevant standards must lie within the institutions as they strive towards excellence and grow more vigorous to support the present learners and prepare to provide future learning 
needs. Encountering this will direct the survival and sustainable development of HEls.

Knowledge and competencies of the workforce indeed elucidate the increase in involvement in a higher level of education. New jobs formed in respect of modern industries against traditional work. Meanwhile, many jobs created require specific industrial skills and ongoing training and development programs. Concerning this, quality assurance in HEls is critical, and the primary responsibility for this effort rests on the institutions' innovation. $\mathrm{HEIs}$, as autonomous entities, must have academic freedom and autonomy to manage their internal affairs. Increasingly HEls are expected to create their practices and processes to ensure the quality of their literary awards and programs. HEls in this century must maintain their academic standards and quality of teaching and learning as part of their evolving approach to the assurance of quality in education. Therefore, HEls must be ready with quality assurance governance.

In describing quality assurance, it is essential to stress the obligation for broad organisational commitment to improvement. The dissemination of good practices and the development of tools to assist in educational improvement accelerated through continuous learning effort among $\mathrm{HEl}$ educators. Educators need to proactively keep pace with discoveries and ideas through spiral networks of learning activities. Engagement in learning to upgrade skills and insight is a norm, not an option in HEls. Educators with their respective expertise work in teams sharing best practices and experiences driving the HEls educational mission. Knowledge management platforms increase knowledge sharing speed that successively helps HEls improve students' learning abilities. Maintaining the institutions' academic freedom and institutional autonomy is vital in assuring the quality of higher education. Teaching and learning are central to the function and undertaking of HEls hence the effectiveness of the various mechanisms for maintaining and improving teaching and learning in HEls must address. Quality and performance in teaching and learning are the most effective means of quality assurance in HEls, often not discussed explicitly.

Quality assurance in HEls and the continuous support in imparting timely knowledge is essential to advancing the legacy of socio-economy progression. The effective teachinglearning process needs a boost since human resource development becomes an effective plan for the recently emerging industrialised and fast-growing economy. With that in mind, HEls must give serious attention to building a learning organisation culture to become a reputable institution. The dramatic expansion in demand for educational programs and the natural desire of the society to assure that their money is well and effectively spend has increased the awareness of the importance of quality assurance in HEls. Thus transforming HEls into successful learning organisations are found relevant in this globally competitive environment in which they exist and operates (Ortenblad \& Koris, 2014).

HEls appear to be facing an even more uncertain future than expected. Following this, more challenges to the assurance of quality and standards will likely emerge during and after the COVID-19 pandemic. Embedding the principles of the learning organisation perhaps improve the management of academic quality and standards through continuous learning efforts. The development of new approaches in education will lead to more 
effective learning and better teaching. It is a significant development because it shows that HEls take their stated commitment to continuous improvement seriously. The maintenance of standards and quality of education brings benefits to all, not least to HEls themselves. The commitment to quality assurance will lead to conscious recognition of strengths and weaknesses and classify areas for further improvement and development.

\section{Learning Organisation Dimensions}

A highly competent workforce obtains a unique consideration in the global knowledge economy due to the pace of technological expansion and rivalry among countries, resulting in the industry making several deliberate decisions about production and investment. Corporate leaders recognise that their human resources are the most crucial component for business success; hence, education and training have become invaluable endeavours. As modern industry demands skilful workers at all levels, HEls must recognise the need for continuous improvement and retrain human resources in response to rapid technological changes within the new global economy. In addition, the workforce must be well equipped with specialised skills and expertise and higher order of thinking skills. HEls worldwide must also devote more time and resources to continuing education and training, which is essential for sustaining competitive advantage. The central mission and objectives of HEls in the twenty-first century and beyond is to develop every individual and society as a whole through the fortification of individual intelligence, and resilience is undeniable. The triumph of this mission and objectives relies mainly on the eminence of education and training, which can be derived primarily by adopting the learning organisation action imperatives by both the public and private HEls. Indeed, new and emerging needs for knowledge resulting from constant technological innovation encourage a significant shift from an outmoded organisation to a learning organisation paradigm that moves away from old thinking and challenges thoughts of effectiveness. Almost two decades ago, Forester (2002, p. 31) stated that educational institutions should have a systematic approach to institutional learning and reward that inspire everyone to participate. These initiatives mirror the way how they induce intellectual curiosity among learners.

The idea of a learning organisation is not new. Senge (1990) popularised with his research and writing on forming a learning organisation with five disciplines. Since then, implications of transforming into a learning organisation for lasting success extensively investigated. From the integrative perspective, the learning organisation is "... one that learns continuously and transforms itself...Learning is a continuous, strategically used process: integrated with, and running parallel to work" (Watkins \& Marsick, 1993, p.8). There are vast perspectives of learning organisation from the literature; however, the common characteristics from the descriptions are that learning organisation is considered an evolving living organism with learning integrated at the different levels: individual, team, and organisation. Transformation automated as the HEls rendezvous with the challenging living environment (Yang et al., 2004). It is crucial to recognise Garvin's (1993) message that many educational institutions effectively generate or acquire new intelligence but are less productive in utilising innovative discovery to prepare for productivity and organisational performance. Eventually, less espouse collective thoughts in facing environmental fluctuations hinders HEls to acclaimed as solid learning organisations. Hence, it impedes 
institutional, professional development. Those HEls who take up this note seriously should have been grown stronger and live steadily.

Watkins and Marsick $(1993,1996)$ proposed a learning organisation model with robust strategies that $\mathrm{HEl}$ leaders should embrace and reap the benefits enjoyed by many businesses. A learning organisation can integrate people and structure to move an organisation in the path of continuous adaptive learning and change. Watkins and Marsick(1993, 1996) suggested seven learning organisation proportions spanning the two constituents of people and structure. It is worth remarking that the characteristics of the learning organisation described by Watkins and Marsick $(1993,1996)$ having practical implications and cover comprehensive perspectives discovered from an extensive review of reports published by scholars and practitioners in the field of learning organisation (Örtenblad, 2002; Yang, Watkins \& Marsick, 2004). In any case, this action imperative model is well worth becoming familiar with among HEls and other organisations. Materialising a learning organisation needs strong engagement from employees at many levels of the institution (Watkins \& Marsick, 1993, 1996), which does not happen immediately but gradually reached over time (Garvin et al.,2008; Garvin,1993). The learning organisation action imperatives direct those responsible for making the journey towards becoming learning organisations a reality in HEls. Some points deliberated about the learning organisation dimensions in the next section.

\section{Learning Organisation Rudiments Create Continuous Learning Opportunities}

Availability of opportunities to learn at a continuous pace involves ongoing education with practical planning for synchronised and non-synchronised learnings. HEls may establish learning platforms that integrate knowledge, experiences, problem-solving decisions, dialogues, and mentors to assist career development. Learning without fail engenders skills, knowledge, understanding, values and capacity to reflect one's professional competencies. HEls leaders need to invest significantly in staff education, training and development and enable educators to progress their skills and careers through broad learning and development. Learning initiatives are dynamic and will evolve based on the needs of the individuals to pursue further expertise in their field (Waeraas, 2021).

Moreover, in keeping with the need to nurture a learning culture, educators' should be supported to enhance their academic or professional qualifications. These encouragements are crucial to create and promote a learning culture dedicated to teamwork and continuous change. In line with these needs, ongoing learning opportunities are available while these institutions progress towards a learning organisation. The development of electronic-based learning capacity will also ensure that access to learning and development is open at all times to every member of staff, wherever they may be. Nevertheless, educators should increasingly accept more control over the development of their learning throughout life and be ready to invest more time, effort and money in advancing knowledge that parallels disruptive technology.

\section{Promote Inquiry and Dialogue}

The goal of starting a conversation is to provide a safe environment for people to ask questions. Frequent communication helps understand behaviour, emotions, values, ideas, 
work experiences, dilemmas, and solutions. Exploration happens when inquire are put forward. It enriches thinking and welcomes continuous and constructive debates to reach better job performance. Many people have encountered benefits through open or even close dialogue sessions. It stimulus positive energy, reduce ambiguity and bring up self-esteems. Watkins and Marsick (1993) are confident that "by telling what is on one's mind, asking questions about its impact, listening for reasoning in people's answers, and keeping open to new viewpoints"(p.13) will spark innovative work behaviour.

Furthermore, because conversations are exploratory, communication becomes critical in recognising the potential in people and nurturing their abilities that benefit all parties. Move along with inquiry, feedback and experimentation within the institution aimed for constructive improvement and not personal attacks. It will be easy to practice inquiry and dialogue in learning organisations since trial and error is not an issue, availability of massive learning support systems, sense of appreciation, recognition, and mutual respect familiarised. Frequent self-evaluation amongst the employees at all levels of HEls, in a way, will back endless networks of communication rooted in the passion for discovery.

\section{Inspire Collaboration and Team Learning}

Primarily team learning is intended towards enhancing team solidity and effectiveness while also promoting knowledge and understanding at the individual level. HEls members must create new insights that are gathered by not working alone but collaboratively. Undeniably, teams and networks use to move new knowledge throughout the institutions. When instructors cooperate, wisdom transfers more effectively, and a culture of cooperation may be fostered by sharing obligations and praises.

Learning the fundamentals of presenting ideas and solutions to encourage other team members effectiveness and efficiency is an excellent point to note. Frequent communication is an essential process that links team members together. When each team strengthens abilities on "framing, reframing, experimenting, crossing boundaries, and creating an integrative perspective" of implicit knowledge, team learning heightens (Watkins \& Marsick, 1993, p.14). The true advantage of learning as a team is integrating techniques and ideas to generate systemic institutional appeal. Learning in team-level settings allows instructors to give social backing to one another while also developing job oriented abilities. Team learning occurs due to eloquent discourse, which might take the shape of dialogues or debates (Senge, 1990). Members of the institution can exchange information and best practices through collaborative work and team learning, resulting in collaboratively built knowledge, performing goals, and achieving the purpose.

\section{Establish Systems to Capture and Share Learning}

Structures bundled with technologies prerequisite within an organisation to manage knowledge, both explicit and implicit. HEls education, research, consulting, training and coaching strategies are excellent examples of explicit knowledge, whereas knowledge, skills, ability and competencies are few tacit knowledge. Knowledge spurred from an individual, however, embodied in teams and organisation. Thus, a highly secured knowledge management system must hoard and retrieve organisational knowledge for decision-making or improve oneself. Watkins and Marsick $(1993,1996)$ observed that learning organisations preserve corporate memory so that even widely dispersed employees learn regardless 
of time and space. Knowledge-sharing efforts enrich the learning process and further lead $\mathrm{HEl}$ educators to move beyond traditional instructional methods that delay competitiveness. Advance knowledge management platforms show how employees within an organisation interact and are committed to sharing information vital for organisational sustain performance. The amount of data captured and the widespread sources matter in learning organisations as knowledge is always learned, preserved, and transmitted consciously, not only during the COVID-19 pandemic. Knowledge sharing can be documents, pictures, multimedia, and various other data formats depending on the digital platform. Technology impacts knowledge management, and it inspires the development of software and system to leverage knowledge strategically in response to demands and challenges. HEls already have plans regarding knowledge management; some prefer to use readily available software and tools, and for others, tailored made is a high preference. In any case, the importance of knowledge management is in memory of leaders managing the HEls. Tools and techniques used during the time of baby boomers almost getting buried in today's advancement.

\section{Empowering People toward a Collective Vision}

Vision driven employees are capable of helping the continued survival of HEls and remain relevant to society. In a learning organisation, steady processes are in place to get closer to the vision while improving the present setbacks. Constant feedback looked forward with more outstanding empowerment practices that lead every member of the HEI towards the vision of their institution. The combined strengths of the employees' empowerment and aspirations towards the vision they hold the institution's future direction. Empowerment also means that members of the organisation have some level of sovereignty in meeting their aspirations. In learning organisations, everyone has an idea of organisation direction, clearly leadership, structured, sufficient financial backup to organise activities, and has the relevant base to work collaboratively (Watkins \& Marsick, 1993, 1996). However, it is not easy to see empowerment succeeding in an organisation that does not fully commit to empowering its workers. For the practice of empowerment to be fruitful, the right culture and environment of trust must exist, allowing people to improve from previous errors. It is not new but good to reinforce that it can retain and sustain its employees' morale and efficiency, with measurable benefits to the institution and society through empowerment. Regular employee gathering to bolster the vision statement is beneficial.

\section{Connecting Organisation to the Environment}

Learning organisation does not happen in a vacuum, or learning occurs without a volatile, uncertain, complex, and ambiguous environment. Intelligence grows as learning organisations gather information outside their workspace that can happen physically or immediately with the potentials brought forward by technologies. Curiosity remains at the heart of exploration and learning (Marquardt, 1996, 2002). Learning occurs at many levels and provides intelligence to adapt and change in response to the needs of industrial revolutions and civilisation. The environment generally implies a wide range of forces influencing the learning organisations, such as political, technological, economic and social, and legislative governance systems. No one standard approach that an organisation could associate with the environment. Learning organisation recognises internal and external environments as interdependent and respond to the demands accordingly (Watkins \& Marsick, 1993, 1996). Employees are part of the organisation's stakeholders, and being responsible internally means they contribute to the dynamics of external members. 
Cyberspace provides the means of interacting with global communities to access, search and use current responsiveness and historical resources. The interconnectivity helps the HEls to grow smarter together with the industry and communities.

\section{Strategic leadership}

Leaders in learning organisations encourage employees involvement and participation in forming a holistic vision that works well for the entire organisation and fulfils the stakeholders' expectations. Most importantly, HEI leaders need to make sure the relevant support and recognition methods are all in place. Essential leadership quality is to place unique directions, unambiguous and achievable with employees citizenship behaviour. With this regard, the HEl leaders should demonstrate a personal mastery that they pursue at all times. The responsibility to learn, discover innovations, challenge own perceptions, and lead others to think beyond their mental traps has always been a practice by leaders in learning organisations. Fostering learning among the employees ultimately will drive the HEls in battling the unprecedented situation while achieving individual, team and essentially collective institutional vision. The traditional leaders approach, top think and bottom react, have been called to put off long ago. Instead, enforce a rhythmic move to everyone think and retort collectively as this mirrors learning organisation (Marquardt, 1996, 2002; Senge, 1990; Yulk, 2002, 2012). Now it is not easy to see any leaders who do not support this practice.

To ensure quality in HEls, leaders commitments towards learning and development and high performance at an express pace are incredibly vital. In today's cybernetic environment, leaders who inspire everyone to support beyond expectation educational assurance are essential. Transformation leaders demonstrate the skills needed to include and lead institutional members to adjust themselves to current modifications. Leadership has a crucial role in developing the potential of $\mathrm{HEI}$ members; enabling them to respond beyond their limits is undeniable (Petriglieri \& Petriglieri, 2015). Furthermore, recognising and adequately rewarding the exemplary contributions of institutional members would strengthen their commitment to attaining the intended objectives. Indeed, leadership would help ensure timely delivery of contemporary education that further direct the industrial revolutions and create advanced information and communication technology stools for modern human living. Leadership is essential to blend other learning organisation dimensions for enduring performance is indisputable.

\section{Conclusion}

It is common to observe increasing demands for contemporary education and assurance of quality in HEls. The internal and external stakeholders have always supported the HEls efforts to review, develop, maintain, and enhance educational provision. Assuring eminence in higher education with an affordable fee while promoting the right talent is a critical challenge for HEls at all times. Meanwhile, the impetus for the HEls is to learn, adapt and evolve. Mechanistic operations of HEls inevitably to industrial revolutions and knowledge economy. Thus the learning organisation tenets are essential to make strategic decisions and proactively engage with uncertainty and changes. A swift response to the recent global COVID-19 pandemics shows that HEls can survive with differentiated educational provisions. Indeed learning organisations can build their future by discoveries of opportunities through networks of learning. In addition, a successful learning organisation consents institutional members to work together to create a structure that adapts as society alters its 
demands. In institutional direction and decision-making, information and knowledge remain critical to further educational goals.

Watkins and Marsick (1993) have designed a learning organisation framework that is vibrant, practical and able to drive the vision to reality. Strategy, leadership, structures, processes, and learning culture fostered to accelerate organisation-wide learning. The learning organisation concept has become more appealing in the past decades, shown significant success. It remains relevant to date-sustainable development requisite seven action imperatives, a well-tested framework for for-profit and not-for-profit organisations, including HEls. A positive contribution to the development of resilient educational entity and keep advancing together with communities in all parts of the globe. This paper concurs with the vast benefaction of the applicability of Watkins and Marsick 's learning organisation model leading to success. As espoused by Watkins and Marsick, the learning organisation model is germane for almost three decades and continue to serve as the theoretical foundation for research on learning culture.

\section{References}

Akella, D. (2021). A learner-centric model of learning organizations. The Learning Organization, 28(1): 71-83. https://doi.org/10.1108/TLO-06-2020-0117

Ashour, S., El-Refae, G. A., \& Zaitoun, E. A. (2021). Post-pandemic higher education: Perspectives from university leaders and educational experts in the United Arab Emirates. Higher Education for the Future, 8(2), 219-238.

https://doi.org/10.1177/23476311211007261

Battistella, C., Cicero, L., \& Preghenella, N. (2021). Sustainable organisational learning in sustainable companies. The Learning Organization, 28(1):15-31. https://doi.org/10.1108/TLO-05-2019-0074

Garvin D. A. (1993). Building a learning organization. Harvard business review, 71(4), 78-91.

Garvin, D. A., Edmondson, A. C., \& Gino, F. (2008). Is yours a learning organization?. Harvard business review, 86(3), 109-134.

Marquardt, M. J. (1996). Building the learning organization. McGraw Hill.

Marquardt, M. J. (2002). Building the learning organization: Mastering the 5 elements for corporate learning ( $2^{\text {nd }}$ ed.). Davies-Black Publishing.

Marsick, V. J., \& Watkins, K. E. (1999). Facilitating learning organization: making learning. Gower.

Örtenblad, A. (2002). A Typology of the idea of learning organization. Management Learning, 33(2), 213-230. https://doi.org/10.1177/1350507602332004

Örtenblad, A., \& Koris, R. (2014). Is the learning organization idea relevant to higher educational institutions? A literature review and a multi-stakeholder contingency approach. International Journal of Educational Management, 28(2): 173-214. https://doi.org/10.1108/IJEM-01-2013-0010

Petriglieri, G., \& Petriglieri, J. L. (2015). Can business schools humanize leadership? Academy of Management Learning \& Education, 14(4), 625-647. https://doi.org/10.5465/amle.2014.0201

Senge, P. M. (1990). The fifth discipline: the art and practice of the learning organization. Doubleday Publishing Group.

Watkins, K. E., \& Marsick, V. J. (1993). Sculpting the learning organization: lessons in the art and science of systematic change. Jossey Bass Publishers. 
Watkins, K. E., \& Marsick, V. J. (1996). In action: creating the learning organization. ASTD Press.

Miller, M. T. (2021). Do learning organizations learn? Higher education institutions and pandemic response strategies. The Learning Organization, 28 (1): 84-93. https://doi.org/10.1108/TLO-09-2020-0159

Waeraas, A. (2021). Understanding change in circulating constructs: collective learning, translation and adaptation. The Learning Organization, 28(1): 1-14. https://doi.org/10.1108/TLO-08-2020-0140

Yang, B., Watkins, K., \& Marsick, V. (2004). The construct of the learning organization: Dimensions, measurement, and validation. Human Resource Development Quarterly, 15(1), 31-56. https://doi.org/10.1002/hrdq.1086

Yorke, M. (1999). Assuring quality and standards in globalised higher education. Quality Assurance in Education, 7(1):14-24. https://doi.org/10.1108/09684889910252496

Yukl, G.(2002). Leadership in organizations (5th ed.). Prentice-Hall.

Yukl, G. (2012). Effective leadership behavior: What we know and what questions need more attention. Academy of Management Perspectives, 26(4), 66-85. https://doi.org/10.5465/amp.2012.0088 